Research Paper

\title{
Reproductive Health Literacy and Its Relationship With Some Demographic Factors in Men Referring to One In- fertility Center in Mashhad City, Iran
}

\author{
Bita Saifi $^{1}$ (D) Zahra Mostafavian ${ }^{2 *}$ (D), Saeed Abtahi ${ }^{3}$ (D), Niloofar Vakili ${ }^{4}$ (D)
}

1. Department of Anatomy, Faculty of Medicine, Mashhad Branch, Islamic Azad University, Mashhad, Iran.

2. Department of Health and Community Medicine, Faculty of Medicine, Mashhad Branch, Islamic Azad University, Mashhad, Iran.

3. Department of Pediatric Cardiology, Faculty of Medicine, Mashhad Branch, Islamic Azad University, Mashhad, Iran.

4. Department of Health and Community Medicine, Faculty of Medicine, Mashhad Branch, Islamic Azad University, Mashhad, Iran.

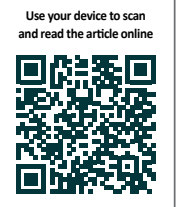

Crtation Saifi B, Mostafavian Z, Abtahi S, Vakili N. Reproductive Health Literacy and Its Relationship With Some Demographic Factors in Men Referring to One Infertility Center in Mashhad City, Iran. Journal of Research \& Health. 2021; 11(6):435442. http://dx.doi.org/10.32598/JRH.11.6.1847.1

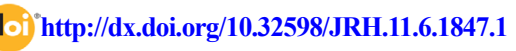

Article info:

Received: 12 Nov 2020

Accepted: 17 Feb 2021

Publish: 01 Dec 2021

\section{Keywords:}

Health literacy, Attitude, Infertility, Men, Iran

\section{ABSTRACT}

Background: Infertility is one of the important concerns for couples. Men have rarely been the focus of research, and their knowledge and attitude have been less studied so far. This study investigated health literacy and attitude in men with infertility.

Methods: In this descriptive-analytic cross-sectional study, 196 men referred to one infertility center in Mashhad City, Iran, in 2019 were selected by a convenience sampling method. The study data were collected using a 20-item health literacy questionnaire and 5 attitude items towards infertility.

The relationships between age, education, occupation, income, duration of infertility, Assisted Reproductive Technologies (ART), history with reproductive health literacy, and attitude were investigated with $t$ test, ANOVA, and linear regression in SPSS v. 20 software at a significance level of less than 0.05 .

Results: The Mean \pm SD age of men was $35.02 \pm 6.06$ years. Their Mean \pm SD reproductive health literacy score $(3.2 \pm 0.3)$ did not show significant relationships with age $(\mathrm{P}=0.336)$, education $(\mathrm{P}=0.33)$, job $(\mathrm{P}=0.493)$, income $(\mathrm{P}=0.856)$, infertility duration $(\mathrm{P}=0.136)$, and history of ART $(\mathrm{P}=0.057)$. All attitude questions were not related to the education and history of ART. Attitude about surrogacy $(\mathrm{P}=0.011)$ and the possibility of separation of each couple in case of infertility $(\mathrm{P}=0.001)(\mathrm{P}=0.015)$ for men and women respectively were different according to age. Most participants chose the answer "I don't know" in the reproductive health literacy questionnaire.

Conclusion: Because of insufficient health literacy of men about infertility, educational planning in this area seems essential.

\footnotetext{
* Corresponding Author:

Zahra Mostafavian, PhD.

Address: Department of Health and Community Medicine, Faculty of Medicine, Mashhad Branch, Islamic Azad University, Mashhad, Iran.

Phone: +98 (915) 5175389
}

E-mail:dr.mostafavian@mshdiau.ac.ir 


\section{Introduction}

nfertility has been one of the most critical problems of human societies throughout I history. This condition has always caused many problems for people, depending on societies' perspectives. Infertility is defined after one year of unprotected sex and has directly and indirectly affected about $10 \%$ of the world's population [1].

The incidence of infertility and its prevalence varies in different regions because of differences in factors, such as age at marriage, polygamy, environmental pollution, alcohol consumption, smoking, and the prevalence of infectious diseases in different communities [2]. In the United States, about 7 million people have infertility [1]. In underdeveloped countries, the prevalence of infertility is much higher than the global average [3, 4]. One of the causes of low fertility is increasing age and having children at older ages [5]. Unfortunately, delay in fertility is associated with an increased risk of infertility and a decrease in the number of children [6]. Issues, such as continuing education, achieving stable living conditions, and reaching individual social maturity, tend to delay fertility [5].

Also, trust in solving infertility problems with the help of Assisted Reproductive Technologies (ART) without being aware of the dangers threatening the mother and fetus has been mentioned as other causes of delay in fertility [6]. Various studies have shown that infertility exists in both sexes. It affects all ages, although it is most common between 19 and $27[3,7]$. More than half of the causes of infertility are due to male factors, such as low sperm count and abnormal sperm shape [8]. However, studies have shown that men are less interested in pursuing and solving infertility [9].

One of the most important reasons for men to neglect infertility is the low health literacy of the population of underdeveloped countries, especially in men, regarding infertility, its causes, and treatment strategies [1]. This superiority in awareness level in women could be due to their higher concerns regarding infertility and the fear of not being able to have a child. Women whose husbands are infertile, experience a lot of stress in their social relationships. This status shows the disrespectful behaviors resulting from the immaturity of families and others. What is worth considering is that even in male infertility, the responsibility for infertility lies with the woman [10]. Health literacy means obtaining health information from reputable sources, interpreting the information correctly, and ultimately using them to improve people's health.
An acceptable level of health literacy allows people to understand better and interpret the various challenges related to their health, and as a result, have a better response to pathogens and take care of themselves and those around them [11]. Reproductive health literacy refers to how people know about fertility information [12]. Evidence shows that people's level of awareness is low about the appropriate age of female fertility, a progressive decrease in their chances of fertility after the age of 34 , and the possible causes of infertility [13].

Studies that have been done so far have rarely focused on men, and their health literacy has been less studied [8]. A study in Sudan that looked at male fertility found that most men did not adjust their lifestyle to improve health and fertility. The researchers recommended more research to understand better this behavior and underlying factors [14].

Considering the importance of each couple's awareness of infertility issue and also the fact that before any intervention in the field of health literacy and necessity to be aware of the current situation, we investigated reproductive health literacy and attitudes toward infertility in men referring to one infertility center in Mashhad City, Iran, in 2019 and its relationship with variables such as age, education, occupation, income, duration of infertility and history of ART.

\section{Methods}

In this cross-sectional study, 196 men who had been referred to one infertility center in Mashhad in 2019 for treating infertility in themselves or their wives were studied. The subjects were included in the study by convenience sampling method. The inclusion criteria were being literate in Persian, first marriage, and primary infertility. The exclusion criteria were having an adopted child and dissatisfaction with participation in the study. The sample size was estimated at 196 based on a reference study [5] in which the Mean $\pm \mathrm{SD}$ of the knowledge score in men was $3.2 \pm 0.27$, with a confidence interval of 0.95 and a power of $80 \%$.

Data collection tools included questionnaires of reproductive health literacy and attitudes toward fertility, as well as a checklist of demographic information. The reproductive health literacy questionnaire consists of 20 questions. This questionnaire is taken from the study of Daniluk [5], and the attitude questionnaire includes 5 questions based on Rouchou's study [7]. The steps of translating the questionnaire into Persian and back translation into English were performed by 2 translators fluent 
in Persian and English. The validity of the questionnaire, including face and content validity, was assessed by 6 professors of community medicine and specialists in reproductive health and embryology and by 10 men referring to the infertility clinic. To evaluate the reliability, 20 eligible people examined the Persian questionnaire. The Cronbach $\alpha$ coefficient for the health literacy section was 0.86 , and for the attitude section was 0.76 , which indicates the optimal reliability of the questionnaire.

Reproductive health literacy questions are scored on a 5 -point Likert scale as $1=$ definitely not, $2=$ probably not, $3=$ I do not know, $4=$ probably yes, and $5=$ definitely yes. In the second part of the questionnaire, which contains questions about the attitude towards infertility, each question has three options: yes, no, and no idea.

After completing the required number of questionnaires by the study participants and collecting them, the data were entered into the statistical software.

Data analysis was done using SPSS v. 20 software. The processed data were expressed as Mean \pm SD and No.(\%). To compare quantitative variables between two groups or more than two groups, after confirming the normal distribution of the data by Kolmogorov-Smirnov test, $t$ test, and ANOVA were used, respectively. A multivariate linear regression test was used to simultaneously examine the independent effects of variables on the knowledge score, and the Chi-square test was used to compare qualitative variables between two or more groups. The significance level of all tests was considered less than $5 \%$.

\section{Results}

The Mean \pm SD age and duration of infertility of the participants were $32 \pm 6$ years (21 to $60 \mathrm{y}$ ) and $3.11 \pm 1.36$ years ( 1 to $7 \mathrm{y}$ ), respectively. Other demographic characteristics and causes of infertility are presented in Table 1.

In univariate analysis, the health literacy score in the study samples was not statistically significant $(\mathrm{P}>0.05)$ regarding age, education, occupation, income, duration of infertility, and history of ART. Also, linear regression analysis showed that the reproductive health literacy score in the study sample had no statistically significant relationship with any of the independent variables $(\mathrm{P}>0.05)$. Table 2 presents the attitude questions and the answers to them by the subjects.

In the Chi-square analysis performed to investigate the relationship between each attitude item and demographic variables, the following results were obtained. The second attitude question (acceptance of surrogacy by the community) and the fourth attitude question (divorce of a woman if her husband cannot have children) had a significant relationship with men's age $(\mathrm{P}=0.011, \mathrm{P}=0.001$, respectively) and the fifth attitude question (divorce of a man if her wife cannot have children) had a significant relationship with men's age $(\mathrm{P}=0.015)$ and the duration of infertility $(\mathrm{P}=0.029)$. None of the attitude items had a statistically significant association with education level, ART history, occupation, and monthly income $(\mathrm{P}>0.05)$.

\section{Discussion}

Our study results showed that infertility health literacy scores in men were not significantly related to age, history of ART, education, duration of infertility, cause of infertility, average monthly income, and occupation. Regarding the acceptance of rented uterus in the community, the results showed that people under 30 more than older people believed in the acceptability of this method in the Iranian-Islamic society. In contrast, regarding the possibility of separation of each couple, if the other party cannot conceive, people over 30 responded more positively than younger people.

Daniluk et al. at the University of British Columbia in Canada studied fertility knowledge and ART in 599 men with childless women. In their study, $71.2 \%$ of men knew that women's fertility decreased after the age of $35,69.2 \%$ considered abortion rates to be higher than normal in women in their 40s, even though they were healthy, and $63.2 \%$ were aware that sexually transmitted diseases, including chlamydia and gonorrhea, increase the risk of infertility. These percentages in our study were $87.8 \%, 55.6 \%, 66.3 \%$, respectively. In Daniluk's study, the level of knowledge of men according to the demographic information of age, education, and income did not differ from each other [5], which were similar to our study findings.

Daumler et al. in Canada, in their study entitled "Men's Awareness of Their Reproductive Power", studied 701 men. The study found that most men $(85 \%)$ believed that they were aware of the reproductive system and fertility, while this group identified only half of the risk factors for infertility. However, they were clearly aware of several risk factors, such as long-term use of steroids (77.8\%), sexually transmitted diseases $(74.3 \%)$, smoking $(67.8 \%)$, and the effect of aging on sperm quality $(69.5 \%)$ [8]. Similar to our study, $66.3 \%$ of men responded correctly to the impact of sexually transmitted diseases, $80.6 \%$ to the effect of smoking on infertility, and $53.8 \%$ answered the impact of age on sperm quality. 
Table 1. Frequency distribution of demographic characteristics in studied men

\begin{tabular}{|c|c|c|}
\hline \multicolumn{2}{|c|}{ Variables } & \multirow{2}{*}{$\begin{array}{l}\text { No. (\%) } \\
29(14.8)\end{array}$} \\
\hline \multirow{5}{*}{ Education } & Less than diploma & \\
\hline & Diploma and Associate degree & $97(49.5)$ \\
\hline & BS & $48(24.5)$ \\
\hline & MS or PhD & $22(11.2)$ \\
\hline & Total & 196(100.0) \\
\hline \multirow{7}{*}{ Job } & Student & $5(2.6)$ \\
\hline & Employee & $58(29.6)$ \\
\hline & Unemployed & $10(5.1)$ \\
\hline & & \\
\hline & Self-employed & $110(56.1)$ \\
\hline & Worker & $13(6.6)$ \\
\hline & Total & 196(100.0) \\
\hline \multirow{5}{*}{ Monthly income (Million) } & $<1$ & $12(6.1)$ \\
\hline & $1-2$ & $62(31.6)$ \\
\hline & $2-4$ & $80(40.8)$ \\
\hline & $>4$ & $42(21.4)$ \\
\hline & Total & 196(100.0) \\
\hline \multirow{5}{*}{ Infertility cause } & Male & $35(17.9)$ \\
\hline & Female & $56(28.6)$ \\
\hline & Both & $31(15.8)$ \\
\hline & Not know & $74(37.8)$ \\
\hline & Total & 196(100.0) \\
\hline \multirow{3}{*}{$\begin{array}{l}\text { Assisted reproductive therapy } \\
\text { history }\end{array}$} & Yes & $85(43.4)$ \\
\hline & No & $111(56.6)$ \\
\hline & Total & 196(100.0) \\
\hline
\end{tabular}

mPA

Also, in the sample study, the general level of fertility knowledge did not differ in terms of most demographic information, including age, occupation, income, education, marital status, having children, and history of ART. This finding is similar to our study.

In Rouchou et al.'s study at Granada College in 2013, 508 male and female students over 16 were surveyed. In this study, the levels of students' knowledge about the causes of infertility and the possible treatment options were assessed. Many of them believed that the causes of infertility affect women more than men, and as a result, women are more prone to infertility [1]. While in our study, $33.7 \%$ of men thought similarly. This difference can be explained in terms of more information of the participants in our study regarding our study population, which included referrals to infertility clinics. In examining students' attitudes, most students believed that neither men nor women should separate from their partners if they are infertile. However, with a difference of 
Table 2. Answers to attitude questions towards infertility in men under study

\begin{tabular}{|c|c|c|c|c|}
\hline \multirow{2}{*}{ Row } & \multirow{2}{*}{ Items } & \multicolumn{3}{|c|}{ No. (\%) } \\
\hline & & Yes & No & I Don't Know \\
\hline 1 & $\begin{array}{l}\text { In your opinion, is having a child with the help of a doctor and medicine } \\
\text { acceptable in society? }\end{array}$ & 186(94.9) & $7(3.6)$ & $3(1.5)$ \\
\hline 2 & $\begin{array}{l}\text { In your opinion, is it socially acceptable in your community to have a } \\
\text { baby with the help of a surrogate (someone who gives birth to a baby for } \\
\text { you)? }\end{array}$ & $68(34.7)$ & $66(33.7)$ & $62(31.6)$ \\
\hline 3 & $\begin{array}{l}\text { In your opinion, if one couple cannot have children, is it better to adopt } \\
\text { another child? }\end{array}$ & $90(45.9)$ & $41(20.9)$ & $65(33.2)$ \\
\hline 4 & $\begin{array}{l}\text { If a woman cannot have a baby, do you think her partner has a } \\
\text { reason to separate from her? }\end{array}$ & $32(16.3)$ & 136(69.4) & $28(13.3)$ \\
\hline 5 & $\begin{array}{l}\text { If a man cannot have a baby, do you think his partner has a reason to } \\
\text { separate from him? }\end{array}$ & $41(20.9)$ & $123(62.8)$ & $32(16.3)$ \\
\hline
\end{tabular}

IRA

$10 \%$, they had a positive opinion about the separation of women in case of male infertility [1]. In our study, there was a similar opinion. About $20.9 \%$ of men answered positively to the possibility of female separation if the male is infertile and $16.3 \%$ to husband separation if the female is infertile. This similarity of results may indicate the importance of women's rights in the present age.

In a cross-sectional study by Gerhard et al. in Atlanta, Georgia, 210 men who were referred to two care clinics were surveyed. The majority of participants $(67 \%)$ believed that infertility is a curable condition and should be treated. A small group (11\%) believed that infertility treatment was dangerous. Also, $43 \%$ believed that infertility reduces the quality of life of men [9]. In our study, $48 \%$ of people answered the question of the risk of IVF for women correctly, which could be due to the increase in men's awareness of this issue through the infertility clinic and infertility treatment process. In this study, there was a significant difference between people with high and low socioeconomic status. Also, Caucasians were more aware of infertility than non-Caucasians. However, after adjusting for variables of age, socioeconomic status, and race, there was no statistically significant difference [9]. This finding was similar to the results of our study, in which the awareness was independent of other variables. However, in our research, different cultures were not studied.

Sadeghipour et al. conducted a study in Tehran in 2006 to assess the differences in knowledge, attitudes, and practices regarding reproductive health issues in 2 groups, Iranian and Afghan men. The results revealed that men in both groups got very low scores for knowledge about reproductive issues. Iranians had a significantly better attitude score. The scores for practices were statistically significantly different between the groups, being better for Iranians, but were still relatively low [15]. Alaee et al.'s study in 2019 entitled "Infertility Knowledge, Attitudes, and Beliefs among Iranian College Students" mentioned that the awareness of female students in some cases is significantly higher than that of males. It also appears that there is an overall perception that women are more likely to become infertile due to any number of causes that are, in fact, of equal risk to both men and women [16].

In Jafari et al.'s study at an infertility center in Mashhad in 2015, there was a significant difference between assisted reproductive devices, such as donated eggs, donated embryos, and rented uterus, and recipient men and women had better attitudes toward these methods. This difference in the attitude of the two groups can indicate the specific position of the recipient group. There was also a significant difference between the knowledge of these two groups about assisted reproductive techniques. This awareness was higher in the recipient group [17].

In Khajavi's study on 216 (77 men and 139 women) infertile couples in Tehran in 2016, 185 samples stated that they had information about surrogacy, while only 31 had good and excellent knowledge. Ninety-nine people had no religious views about this method. The attitude of 90 people towards the priority of renting a uterus from family and friends was negative. Also, 144 people agreed with the insurance support. Most people had a negative attitude towards raising emotional, legal, and religious issues of the pregnant uterus. Still, their attitude towards solving financial problems and expenses and insurance support was positive [18].

\section{Conclusion}

The knowledge level scores of study participants who had different levels of job and university degrees were the 
same, and the average score of most knowledge questions was around 3, which means that their answers to most questions were "I don't know". Therefore, information about infertility in this group of men is low, and the need is felt for educational planning in this regard, especially in infertility treatment centers for specific groups and also through the public media for the general public.

One of the limitations of this study is that it is performed in one infertility treatment center. To increase the power of generalizing the data to the community, it is necessary to conduct a multi-center study in different parts of Iran. It is suggested that a study with similar demographic characteristics be designed to assess the awareness of men who have not been referred to an infertility clinic and compare the results with our results. This comparison is important as it helps us to understand the role of infertility clinics to inform infertile people and do appropriate planning for informing at different levels of society.

\section{Ethical Considerations}

\section{Compliance with ethical guidelines}

The present study was approved by the ethics committee of the Medical School of the Islamic Azad University, Mashhad Branch (Code: IR.IAU.MSHD.REC.1397.020).

\section{Funding}

This research did not receive any grant from funding agencies in the public, commercial, or non-profit sectors.

\section{Authors' contributions}

Conceptualization and supervision: Bita Saifi and Saeed Abtahi; Methodology: Zahra Mostafavian; Investigation, writing-original draft, and writing-review \& editing: All authors; Data collection: Niloofar Vakili and Bita Saif; Data analysis: Zahra Mostafavian.

\section{Conflict of interest}

The authors declared no conflict of interest

\section{Acknowledgments}

We would like to thank the esteemed staff of the Infertility Center and all men who participated in this project.

\section{References}

[1] Rouchou B, Forde MS. Infertility knowledge, attitudes, and beliefs of college students in Grenada. Science Journal of Public Health. 2015; 3(3):353. [DOI:10.11648/j.sjph.20150303.18]

[2] Karimpour A, Esmaeelnezhad Moghadam A, Moslemizadeh N, Mousanezhad N, Peyvandi S, Gahandar M.[Incidence and main causes of infertility in patients attending the infertility center of Imam khomeini hospital in 2002-2004 (Persian)]. Journal of Mazandaran University of Medical Sciences. 2005 15(49):44-9. http:/ /jmums.mazums.ac.ir/article-1-790-en.html

[3] Mohammad K, Ardalan A. [An overview of the epidemiology of primary infertility in Iran (Persian)]. Journal of Reproduction \& Infertility. 2009; 10(3):213-6. [PMID][ PMCID]

[4] Choobineh H, Sadighi Gilani M, Hassanzadeh G, Saeepour N, Habibi M, Falahi P,et al. [Assessment of socio-demographic characteristics of infertile men who referred to Shariati hospital, Tehran, Iran (Persian)]. The Iranian Journal of Obstetrics, Gynecology and Infertility. 2013; 16(47.48):6-12. [DOI:10.22038/ijogi.2013.789]

[5] Daniluk JC, Koert E. The other side of the fertility coin: A comparison of childless men's and women's knowledge of fertility and assisted reproductive technology. Fertility and Sterility. 2013; 99(3):839-46. [DOI:10.1016/j.fertnstert.2012.10.033] [PMID]

[6] Daniluk JC, Koert E. Fertility awareness online: The efficacy of a fertility education website in increasing knowledge and changing fertility beliefs. Human Reproduction. 2015; 30(2):353-63. [DOI:10.1093/humrep/deu328] [PMID] [PMCID]

[7] Rouchou B. Consequences of infertility in developing countries. Perspectives in Public Health. 2013; 133(3):174-9. [DOI:10.1177/1757913912472415] [PMID]

[8] Daumler D, Chan P, Lo KC, Takefman J, Zelkowitz P. Men's knowledge of their own fertility: A population-based survey examining the awareness of factors that are associated with male infertility. Human Reproduction. 2016; 31(12):2781-90 [DOI:10.1093/humrep/dew265] [PMID] [PMCID]

[9] Gerhard RS, Ritenour CW, Goodman M, Vashi D, Hsiao W. Awareness of and attitudes towards infertility and its treatment: A cross-sectional survey of men in a United States primary care population. Asian Journal of Andrology. 2014; 16(6):858-63. [DOI:10.4103/1008-682X.132782] [PMID] [PMCID]

[10] Talaiekhozani A, Alaee S, Ziaei G, Mir M, Yazdan M, Sadeghi Ataabadi M. [Knowledge of Men and Women about Infertility Risk Factors (Persian)]. Iranian Journal of Health, Safety and Environment. 2016; 3(4):600-6. http://www.ijhse. $\mathrm{ir} /$ index.php/IJHSE/article/view/170

[11] Peyvand M, Kargar S, Hajizade F. [The role of health literacy promotion in epidemic control corona 19 (Persian)] Journal of Health Literacy. 2020; 5(1):9-11. [DOI:10.22038/ jhl.2020.47609.1109]

[12] Barron ML. Fertility literacy for men in primary care settings. The Journal for Nurse Practitioner. 2013; 9(3):155-60. [DOI:10.1016/j.nurpra.2012.10.002]

[13] Bunting L, Tsibulsky I, Boivin J. Fertility knowledge and beliefs about fertility treatment: Findings from the International Fertility Decision-making Study. Human Reproduction. 2013; 28(2):385-97. [DOI:10.1093/humrep/des402] [PMID] 
[14] Bodin M, Käll L, Tydén T, Stern J, Drevin J, Larsson M. Exploring men's pregnancy-planning behaviour and fertility knowledge: A survey among fathers in Sweden. Upsala Journal of Meddical Science. 2017; 122(2):127-35. [DOI:0.1080/030 09734.2017.1316531] [PMID] [PMCID]

[15] Sadeghipour Roudsari HR, Sherafat-Kazemzadeh R Rezaeie M, Derakhshan M. [Reproductive health knowledge, attitudes and practices of Iranian and Afghan men in Tehran Province (Persian)]. Eastern Mediterraneu Health Journal. 2006; 12(6):862-72. http://www.emro.who.int/emhj-volume-12-2006/volume-12-issue-6/reproductive-health.html

[16] Alaee S, Yousefian E, Talaiekhozani A, Ziaee GR, Homayoon $\mathrm{H}$. [Infertility knowledge, attitudes, and beliefs among iranian college students (Persian)]. Journal of Environmental Treatment Techniques. 2019; 7(1):171-8. http://jett.dormaj. com/Volume7_Issue1.html

[17] Jafari H, LatifNejad roudsari R, Taghipour A, Khadem Ghaebi N, EbrahimZadeh S. [Comparison of knowledge and attitude towards reproductive donation procedures between recipient and non-recipient infertile couples at Mashhad Infertility Center (Persian)]. Journal of TorbatHeydariyeh University of Medical Sciences. 2015; 3(2):16-25. http://jms. thums.ac.ir/article-1-82-en.html

[18] Khajavi Shojaee K, Davati A, Hadavand S, Bahrami M. [Knowledge and attitude of patients about the use of surrogacy as treatment method of infertile couples - Mostafa Khomeini hospital in 2016 (Persian)]. The Iranian Journal of Obstetrics, Gynecology and Infertility.2017; 20(1):31-42. [DOI:10.22038/ijogi.2017.8622] 
This Page Intentionally Left Blank 